\title{
Acoustic Emission of Structural Materials Exposed to Open Flames
}

William Grosshandler

Margaret Jackson 



\section{Acoustic Emission of Structural Materials Exposed to Open Flames}

William Grosshandler

Margaret Jackson

December 1992

Building and Fire Research Laboratory

National Institute of Standards and Technology

Gaithersburg, MD 20899

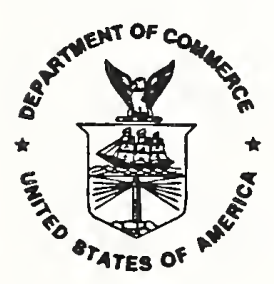

U.S. Department of Commerce

Barbara Hackman Franklin, Secretary

Technology Administration

Robert M. White, Under Secretary for Technology

National Institute of Standards and Technology

John W. Lyons, Director 



\section{TABLE OF CONTENTS}

Page

LIST OF FIGURES $\ldots \ldots \ldots \ldots \ldots \ldots \ldots \ldots \ldots \ldots \ldots \ldots \ldots \ldots \ldots$

LIST OF TABLES $\ldots \ldots \ldots \ldots \ldots \ldots \ldots \ldots \ldots \ldots \ldots \ldots$

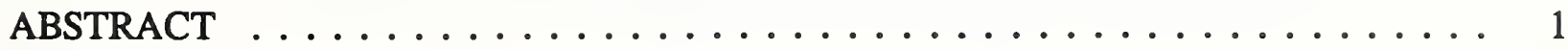

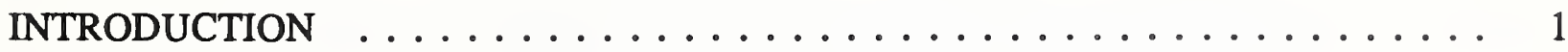

THE ACOUSTIC EMISSION PROCESS $\ldots \ldots \ldots \ldots \ldots \ldots \ldots \ldots$

EXPERIMENTAL APPARATUS AND OPERATING PROCEDURE $\ldots \ldots \ldots \ldots \ldots$

EXPERIMENTAL RESULTS $\ldots \ldots \ldots \ldots \ldots \ldots \ldots \ldots \ldots$

Effect of Material . . . . . . . . . . . . . . . . 10

Effect of Heat Flux .......................... 15

OBSERVATIONS AND CONCLUSIONS $\ldots \ldots \ldots \ldots \ldots \ldots \ldots \ldots$

ACKNOWLEDGEMENT . . . . . . . . . . . . . . . . . . . . . . . 19

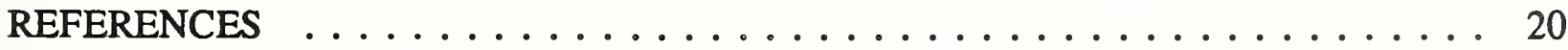


Figure 1. Elements of an acoustic emission signal $\ldots \ldots \ldots \ldots \ldots \ldots$

Figure $2 . \quad$ Experimental facility for measuring $\ldots \ldots \ldots \ldots \ldots \ldots$

Figure 3. Sample showing location of flame and AE transducers ......... 8

Figure 4. Number of emissions and cumulative energy from $13 \mathrm{~mm}$ thick plywood sample heated with $1.1 \mathrm{~kW}$ flame $\ldots \ldots \ldots \ldots \ldots 11$

Figure 5. A comparison of AE events from duplicate samples of $13 \mathrm{~mm}$ thick plywood under identical operating conditions .......... 12

Figure 6. The number of AE events and the cumulative energy released for the fir $2 x 4$ exposed to the maximum heat flux . . . . . . . 17

Figure 7. The effect of heat flux (estimated from eq. 2) on the number of emissions and the cumulative energy released from fire $2 \times 4$ samples. Solid circles are the number of emissions, $\mathrm{N}$, and open circles are the energy, $\mathrm{E} \ldots$ 


\section{LIST OF TABLES}

Page

Table 1. Materials tested $\ldots \ldots \ldots \ldots \ldots \ldots \ldots \ldots$

Table 2. Summary of accumulated energy and number of emissions for $13 \mathrm{~mm}$

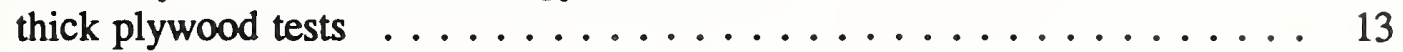

Table 3. Effect of material thickness of AE from plywood ........... 14 


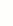




\title{
Acoustic Emission of Structural Materials Exposed to Open Flames
}

\author{
William Grosshandler \\ Margaret Jackson
}

Building and Fire Research Laboratory

National Institute of Standards and Technology

Gaithersburg, Maryland 20899

\begin{abstract}
The use of acoustic emission (AE) as an early indicator of a hidden structural fire has been investigated and found to be a viable, but undeveloped, concept. Piezoelectric transducers have been mounted directly on $0.5 \mathrm{~m}$ long, simply supported beams of different structural materials (aluminum, gypsum board, wood and plastic), and have been used to record ultrasonic events resulting from a small flame placed under the beam. The number of $\mathrm{AE}$ events in a minute and the cumulative energy released during the heating cycle provide a good measure of the overheated state of some of these materials even before a temperature increase is indicated. The measured signals varied in energy and number with the type of material, the thickness of the specimen and heat flux. Wood was particularly susceptible to acoustic emission, producing more than 1000 events per minute in a solid fir board and $30 / \mathrm{min}$ in a $13 \mathrm{~mm}$ thick plywood when the flame exceeded $1.0 \mathrm{~kW}$. A gypsum board produced 16 events in a minute. An aluminum plate did not respond above the background level ( 0.3 events/minute) even though it reached the highest temperature. The differences in cumulative energy were equally striking, with the plywood being four times more energetic than the gypsum board even though the heating period for the wood was half as long, and 30 times more energetic than the aluminum. The critical issues which remain to be investigated before this technique can be adapted to practical fire detection applications are mentioned.
\end{abstract}

\section{INTRODUCTION}

Electromagnetic radiation has long been used as a means to sense the presence of a fire, or to probe the temperature of the products of combustion and exposed surfaces. To a much more limited extent, acoustic radiation has also been considered as an indicator of a fire. The low acoustic frequencies are easily observed as flicker in a flame, and are due to the shedding of vortex structures from the base of the fire. These structures have been studied extensively ${ }^{1}$ 
and have been shown to be periodic with a frequency inversely related to the square root of the circumference of the burning fuel surface, covering the spectrum from about $1.0 \mathrm{~Hz}$ to $10 \mathrm{~Hz}$ as the effective diameter decreases from 2.0 to $0.02 \mathrm{~m}$. Detriche and Langore ${ }^{2}$ compared the acoustic signal from a small pool of burning alcohol to the background noise in the laboratory and measured a $20 \mathrm{~dB}$ enhancement at $2 \mathrm{~Hz}$. The sensitivity increased as the square of the distance of the microphone from the base of the fire decreased, and they concluded that the technique was promising for background noise levels below $70 \mathrm{~dB}$.

The sound emitted by high speed turbulent jet flames, investigated primarily because it is an undesirable byproduct of gas turbine engines, covers a range of much higher frequencies. Ramohalli ${ }^{3}$ was intent on using the acoustic spectrum up to $20 \mathrm{kHz}$ to evaluate the operation of a furnace burner. He showed that the ratio of high frequency to low frequency power could be used to identify changes in burner stoichiometry, and that these ratios were insensitive to microphone location and small changes in burner geometry. Because the high frequencies are associated with small scale, high intensity turbulence, this part of the spectrum would be less useful for monitoring ignition or the early portion of fire growth.

Redding ${ }^{4}$ made use of the speed of sound rather than its frequency to detect the presence of a fire. A modulated ultrasonic beam was directed across the test room toward a high frequency transducer. The lag in phase between the detector and source was used to determine the transit time, from which the sonic velocity was computed. Because the speed of sound increases with temperature to the half-power, a source of heat anywhere along the transmission path can be detected. Such a technique could find application to large area protection schemes and might be particularly valuable in dust or smoke obscured environments.

The heat produced by a smoldering fire or by an electrical circuit overload will cause the surrounding materials to expand. If the affected components are constrained in a structure of dissimilar material (eg., circuit boards mounted on a steel frame), the stressed material may emit sound at frequencies up to $500 \mathrm{kHz}$ when the stress is suddenly relieved. There is a characteristic acoustic signature associated with this process which can be used to detect a serious overheating event prior to ignition. The bubbling of a polymer during heating could be due to a phase change or thermal decomposition, and is observed to be quite vigorous within a short time after flaming ignition. The bursting of the bubbles produces sound which would also be of use to detect the early stage of a fire.

As pointed out by Grosshandler a successful acoustic fire sensor would have several advantages:

Because it measures a field phenomenon, it has the potential of large volume coverage.

- Obscuration of the room by dust and smoke would not degrade its performance.

- The early stage of a deep-seated fire may be detected more quickly by the sounds associated with thermal expansion than by the products of combustion or infrared 


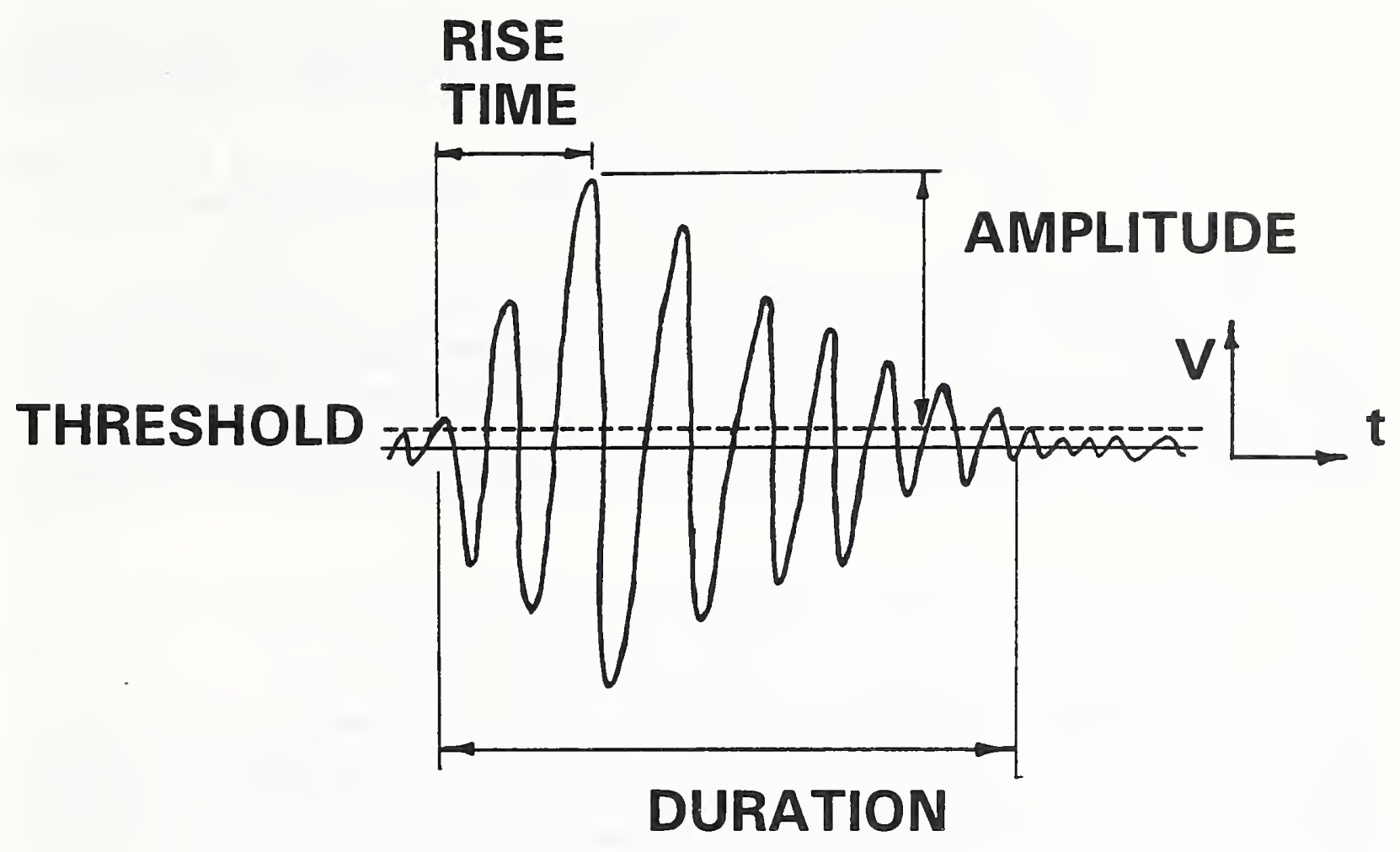

FREQUENCY:

NUMBER OF ZERO CROSSINGS/DURATION

ENERGY:

$\int V(t)^{2} d t$

Figure 1. Elements of an acoustic emission signal 
images, because the acoustic signal travels at the speed of sound while the transport of temperature and products of combustion are controlled by diffusion and convection.

- An acoustic sensor could supply information on the status of a room (people present/absent, electric motor on/off, ventilation fan operating/not operating) which would be useful to an integrated, intelligent detection system.

The objective of the current study is to assess the viability of using the acoustic signal emitted by a variety of structural materials exposed to nonuniform heating as an early indicator of a fire. In the section that follows, the acoustic emission (AE) process and its application to fire detection will be discussed. The experimental facility and procedure will then be described. Finally, the results of a series of tests will be presented and the implications for fire protection will be mentioned.

\section{THE ACOUSTIC EMISSION PROCESS}

Acoustic emission has been used for decades to characterize fracture mechanisms and locate defects in structures. Wadley ${ }^{6}$ and Wadley and Simmons ${ }^{7}$ provide an excellent description of the microscopic origins of the emission process and a review of the theory underlying various applications of AE. A discussion by Wade et al. ${ }^{8}$ presents some more recent and novel uses for variants of the technique.

The source of acoustic emission is the microscopic change in stress which occurs as a solid object moves towards its internal mechanical equilibrium state, with the displacement generating an elastic wave which propagates at the local speed of sound ${ }^{6}$. A piezoelectric transducer placed distant from the location of the original stress relief converts the small motion of the wave to a voltage which, if sufficient in magnitude, can be amplified and measured. An acoustic emission event can be described by its rise time, amplitude, frequency, duration, and energy. Figure 1 is a schematic of the voltage signal produced by a typical event. The frequency measured depends upon the natural frequency of the crystal, and the other parameters vary with the strength of the source, the distance between the source and transducer, and the material properties.

A change in temperature gradient generates stress in an object due to unequal thermal expansion, making $\mathrm{AE}$ a valuable tool for monitoring materials processing operations which generate heat. Clough et al. ${ }^{9}$ studied the behavior of aluminum exposed to electron beam heating. $\mathrm{Wu}^{10}$ was interested in using the acoustic emission from polymeric composites exposed to laser heating to determine the strength of the fiber bonding in the materials.

The strength of a thermoacoustic source depends upon the material properties and the rate at which heat is added. For the instantaneous release of the energy absorbed by a surface when exposed to the pulse of a laser, the stress-wave energy, $e_{\mathrm{s}}$, is directly related to the square of 
the laser energy ${ }^{11}$. Replacing the laser energy with the product of the heat flux from a flame impinging on the surface times the duration of heating, qt, the following relationship indicates how the strength of the source is affected by the material properties:

$$
\mathrm{e}_{\mathrm{z}} \approx(\Gamma B v)^{2} /\left(\mathrm{ckC}_{\mathrm{p}}\right)(\mathrm{qt})^{2}
$$

The first term, $\Gamma B v$, is the product of the bulk modulus, the coefficient of thermal expansion and the specific volume of the solid. The denominator is the product of the sonic velocity, $\mathrm{c}$, the thermal conductivity, $\mathrm{k}$, and the specific heat, $\mathrm{C}_{\mathrm{p}}$. The power which is actually transmitted to a remote transducer from the source will be proportional to $e_{3}$ if the internal dissipation is much less than the losses at the supports and air interface. For large internal damping, the power reaching the transducer is diminished in proportion to the specimen volume and material viscosity ${ }^{11}$.

The parameter $(\Gamma B v)^{2} /\left(\mathrm{ckC}_{\mathrm{p}}\right)$ can be computed for aluminum to be $7.6 \times 10^{-4} \mathrm{~s}^{2} / \mathrm{kg}$. For the other materials tested, the properties are not fully tabulated and are not specimenindependent. By using data from a variety of references, it can be estimated that $(\Gamma \beta v)^{2} /\left(\mathrm{ckC}_{\mathrm{p}}\right)$ is about three orders-of-magnitude larger $\left(0.1\right.$ to $\left.1.0 \mathrm{~s}^{2} / \mathrm{kg}\right)$ for wood, plastics and gypsum board. The internal dissipation of different materials can be estimated from the decay, or ringdown, of an AE signal and the speed of sound in the material. For a fixed excitation the ringdown period is related to the duration of the event (see Figure 1). The duration for aluminum is two to three times longer than for the other materials studied here. Taking into consideration the local speed of sound, the dissipation of wood, gypsum and plastic is estimated to be about five times larger than for aluminum.

A nonhomogeneous or composite material will contain many more defects around which stresses can be relieved. The number of defects per unit volume is highly variable in a heterogeneous material such as wood or gypsum board, and generally impossible to quantify. What can be said is that the number of sources for $\mathrm{AE}$ are likely to be high for materials like wood and gypsum, and relatively low for materials like thermoplastic polymers and metals. Further, when heated, plastic materials will undergo phase transitions more quickly than metals, producing additional acoustic emissions.

\section{EXPERIMENTAL APPARATUS AND OPERATING PROCEDURE}

The experimental apparatus consists of a rectangular beam of the material to be tested, acoustic emission measuring equipment, thermocouples, and a Meeker burner. The different materials examined are described in Table 1. A sketch of the facility is shown in Figure 2. 


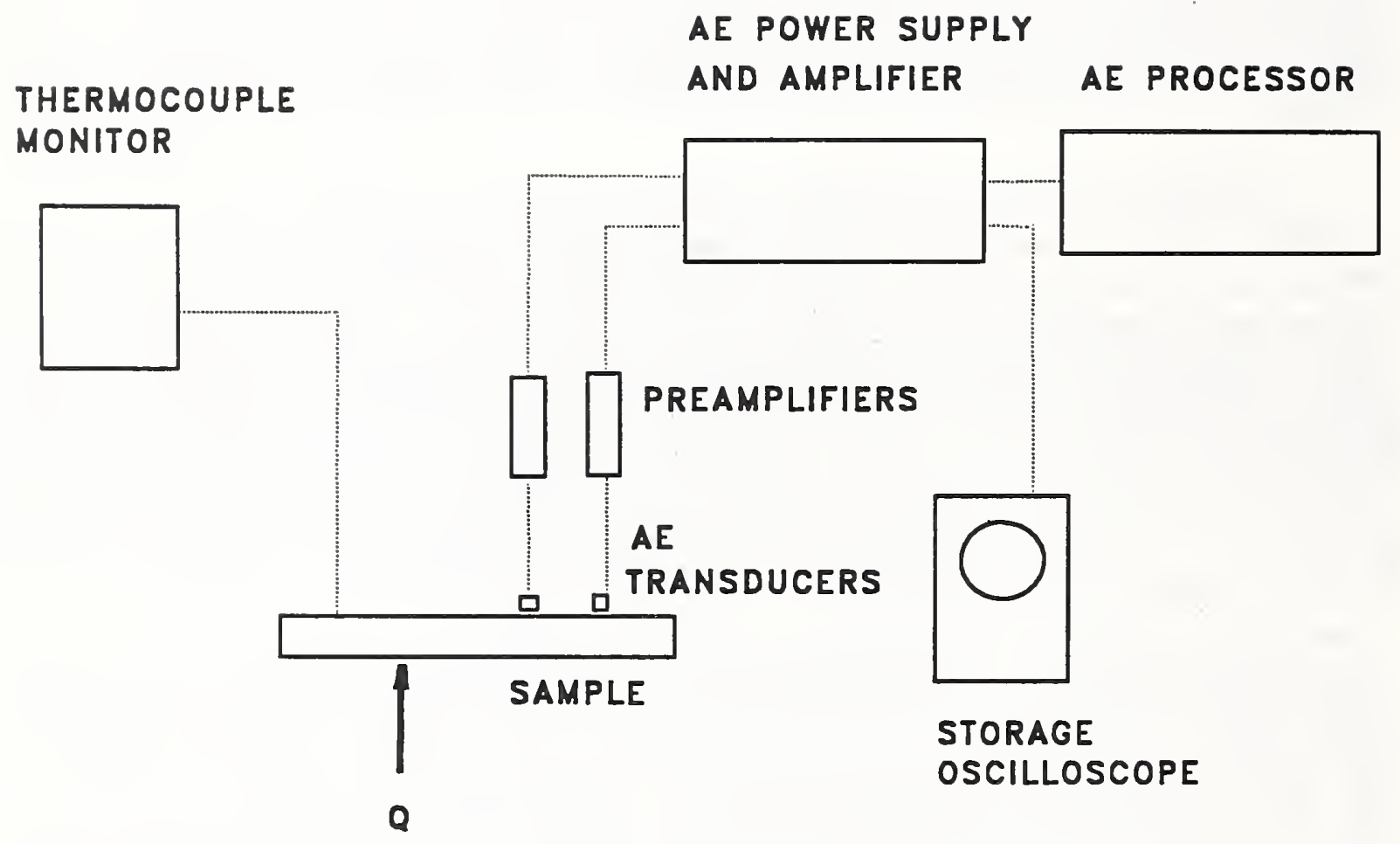

Figure 2. Experimental facility for measuring acoustic emission from heated samples 
Two Physical Acoustic Corporation piezoelectric transducers ${ }^{*}$ were mounted directly on the sample beam, coupled to the top horizontal surface with silicone vacuum grease. The signals from the transducers passed through PAC model 1220 A preamplifiers and a PAC model 3000 power supply, amplifier and signal processor. A storage oscilloscope was used to capture the AE signal.

A chromel/alumel thermocouple was attached with high temperature tape adjacent to the transducers to compare the thermal response of the material to the time it took for the acoustic signal to be detected. A second thermocouple was located between the heat source and the detector as an earlier measure of the heat flow and to determine the relative thermal response of the different materials to the same flame conditions. The top lip of the Meeker burner was situated $0.1 \mathrm{~m}$ below the beam and $0.3 \mathrm{~m}$ to the left of the AE transducers, as shown in Figure 3. This location was chosen because it was far enough from the supports to allow the flame to freely impinge on the surface of the specimen, and far enough from the AE transducers to allow them to be maintained close to isothermal during the test. The natural gas flow to the burner was monitored with a GCA/Precision Scientific wet test meter and manometer.

Two concrete blocks were placed $0.50 \mathrm{~m}$ apart upon $12 \mathrm{~mm}$ thick layers of neoprene foam. The sample beam was located on top of the blocks, isolated from the blocks with another layer of neoprene. Two bricks were placed on each end of the $0.50 \mathrm{~m}$ span to fix the sample in place during the heating period. The transducers were attached with just enough silicone grease to keep the sensors secure during the test.

The response of the AE signal processor depends strongly on the threshold and amplifier settings. Following a series of preliminary tests, an amplification of $+86 \mathrm{~dB}$ (including +60 $\mathrm{dB}$ in the preamplifier) and a threshold level of $0.2 \mathrm{~V}$ were chosen. Changes in the dead time, time base and update rate had little effect on the output, and were fixed at $1.0 \mathrm{~ms}, 1.0 \mathrm{~ms}$, and $20 /$ s, respectively, for the duration of the tests.

Background acoustic emission was collected for two minutes prior to beginning the test. The gas flow was set to the predetermined level (1.1 to $2.21 / \mathrm{min}$ at ambient conditions) and the burner was placed under the sample along the centerline, $0.10 \mathrm{~m}$ from the midpoint of the span and $0.30 \mathrm{~m}$ away from the $\mathrm{AE}$ sensors (see Figure 3). The temperature was measured on two

- Certain commercial products are identified in this report in order to adequately specify equipment used. Such identification does not imply recommendation by the National Institute of Standards and Technology, nor does it imply that this equipment is the best available for the purpose. 

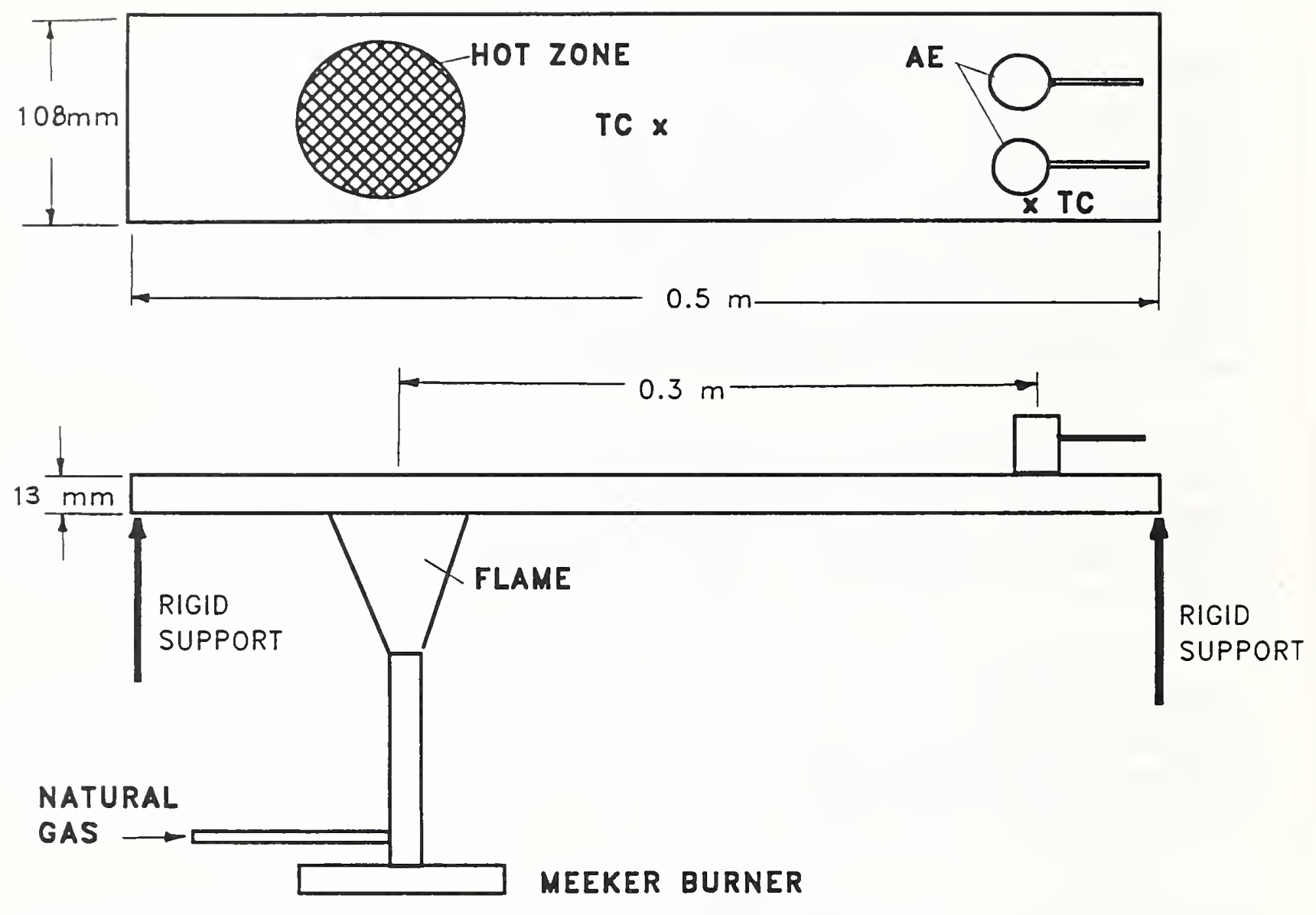

Figure 3. Sample showing location of flame and AE transducers 
Table 1. Materials tested

\begin{tabular}{|c|c|c|c|c|}
\hline Test & Material & Size & Heating Rate & Heating Time \\
\hline ALUM2 & aluminum & $2 \times 108 \mathrm{~mm}$ & high & $120 s$ \\
\hline ALUM13 & aluminum & $13 \times 108 \mathrm{~mm}$ & high & \\
\hline PMMA & $\begin{array}{l}\text { poly-methyl- } \\
\text { methacrylate/ } \\
\text { aluminum }\end{array}$ & $\begin{array}{l}6 \text { (PMMA)/2 (al) } \\
\times 108 \mathrm{~mm}\end{array}$ & high & $120 \mathrm{~s}$ \\
\hline PVC & $\begin{array}{l}\text { poly-vinyl- } \\
\text { chloride/alumi- } \\
\text { num }\end{array}$ & $\begin{array}{l}6(\mathrm{PVC}) / 2 \text { (al) } \\
\times 108 \mathrm{~mm}\end{array}$ & high & $120 \mathrm{~s}$ \\
\hline $\mathrm{CB}$ & $\begin{array}{l}\text { phenolic circuit } \\
\text { board }\end{array}$ & $2 \times 120 \mathrm{~mm}$ & low & $45 \mathrm{~s}$ \\
\hline $2 X 4$ & douglas fir & $37 \times 88 \mathrm{~mm}$ & low to high & $120 \mathrm{~s}$ \\
\hline PLY6 & (3)plywood & $6 \times 108 \mathrm{~mm}$ & high & $120 \mathrm{~s}$ \\
\hline PLY13 & (5)plywood & $13 \times 108 \mathrm{~mm}$ & high & $120 \mathrm{~s}$ \\
\hline PLY19 & (5)plywood & $19 \times 108 \mathrm{~mm}$ & high & $120 \mathrm{~s}$ \\
\hline GYP & gypsum board & $13 \times 108 \mathrm{~mm}$ & high & $240 s$ \\
\hline
\end{tabular}

channels of a Doric Multipoint Selector digital thermometer and recorded manually every thirty seconds. At the end of the heating period the Meeker burner was removed. If the sample had ignited it was allowed to burn while data continued to be collected, and was then extinguished with $\mathrm{CO}_{2}$ or simply by blowing on it.

\section{EXPERIMENTAL RESULTS}

The number of AE events should increase with the number of defects in a material, and, according to eq. 1 , the energy released from a single acoustic emission will vary with the material type and heat flux. The strength of a signal that is actually picked up by the transducer from a particular emission will depend upon the extent of attenuation in the beam. Experiments were designed to verify the relationship in eq. 1 and to assess the relative attenuation rates of the materials in Table 1. An important issue is the amount of variation that is likely among similar samples. The key parameters used to characterize the AE activity during the time which the material is exposed to the flame are the cumulative energy released, $\mathrm{E}$, and the number of emissions, $\mathbf{N}$. 


\section{Effect of Material}

The materials examined include a metal, three plastics, two different wood products, and a gypsum board. On the upper surface of the beams at the location of the AE sensors, the temperature increased only $0.3 \pm 0.1 \mathrm{~K}$ after two minutes of heating for all the materials except for the $6 \mathrm{~mm}$ plywood (which increased $1.4 \mathrm{~K}$ ) and the $2 \mathrm{~mm}$ thick aluminum plate (which increased $7.8 \mathrm{~K}$ ). The peak temperature at the point of flame impingement was not measured, but the heat was sufficient to cause flaming or charring of all the materials other than the aluminum. In no case did the flames extend beyond the midpoint of the span.

The different thermal properties of the samples lead to large differences in the temperatures attained at the midpoint of the span for the same nominal flame size of $1.17 \mathrm{~kW}$. For example, the temperature increase measured by the midpoint thermocouple at the end of the two minute heating period varied from $22 \mathrm{~K}$ for the $6 \mathrm{~mm}$ plywood sample to $4 \mathrm{~K}$ for the PMMA. The $13 \mathrm{~mm}$ thick aluminum increased its midpoint temperature about $16 \mathrm{~K}$, while the gypsum board, PVC and $13 \mathrm{~mm}$ thick plywood had temperature increases of 5 to $7 \mathrm{~K}$.

A typical response of the AE sensors to the application of the flame to the beam is shown in Figures $4 \mathrm{a}$ and $\mathrm{b}$. The sample is $13 \mathrm{~mm}$ thick plywood and the heating rate is at its highest value (1.17 kW flame). A small amount of energy is released almost instantly, followed by a steady accumulation up to 68 seconds, when a noticeable jump occurs. By the end of the heating period the cumulative energy is 145 (arbitrary units). When the flame is removed, the acoustic emission activity increases substantially with the onset of cooling.

The release of acoustic energy is a statistical event, especially in a composite material, so that the number of events and cumulative energy vary greatly from one sample to the next. This is demonstrated in Figure 5, where $\mathrm{N}$ is plotted as a function of time for four replicates of the $13 \mathrm{~mm}$ thick plywood samples. The dramatic increase in number of emissions after the flame is extinguished at $120 \mathrm{~s}$ is evident, and occurred for all samples, flammable or not. The cumulative energy at the end of the heating period and the number of emissions per minute during the two minute heating period and the following one minute cooling period are shown in Table 2. There is a trend towards decreasing emissions with test number, which could be associated with the latter (higher number) samples being dryer since no attempt was made to condition the wood. The number of knots in each sample, the particular board from which they were cut, and whether or not the piece was from the middle or edge of the board may all influence the amount of acoustic activity to be expected. The placement of the AE sensor on the sample also affected the signal, with one channel typically accumulating $30 \%$ more energy than the other over the course of the heating period.

The significance of different material thicknesses was investigated using a 2 and $13 \mathrm{~mm}$ aluminum beam, and 6,13 , and $19 \mathrm{~mm}$ thick plywood, all exposed to the same flame. The 2 $\mathrm{mm}$ thick aluminum produced between 3 and 8 emissions/min during the first 30 seconds of heating; the tests were terminated beyond that time because the high temperatures caused the 

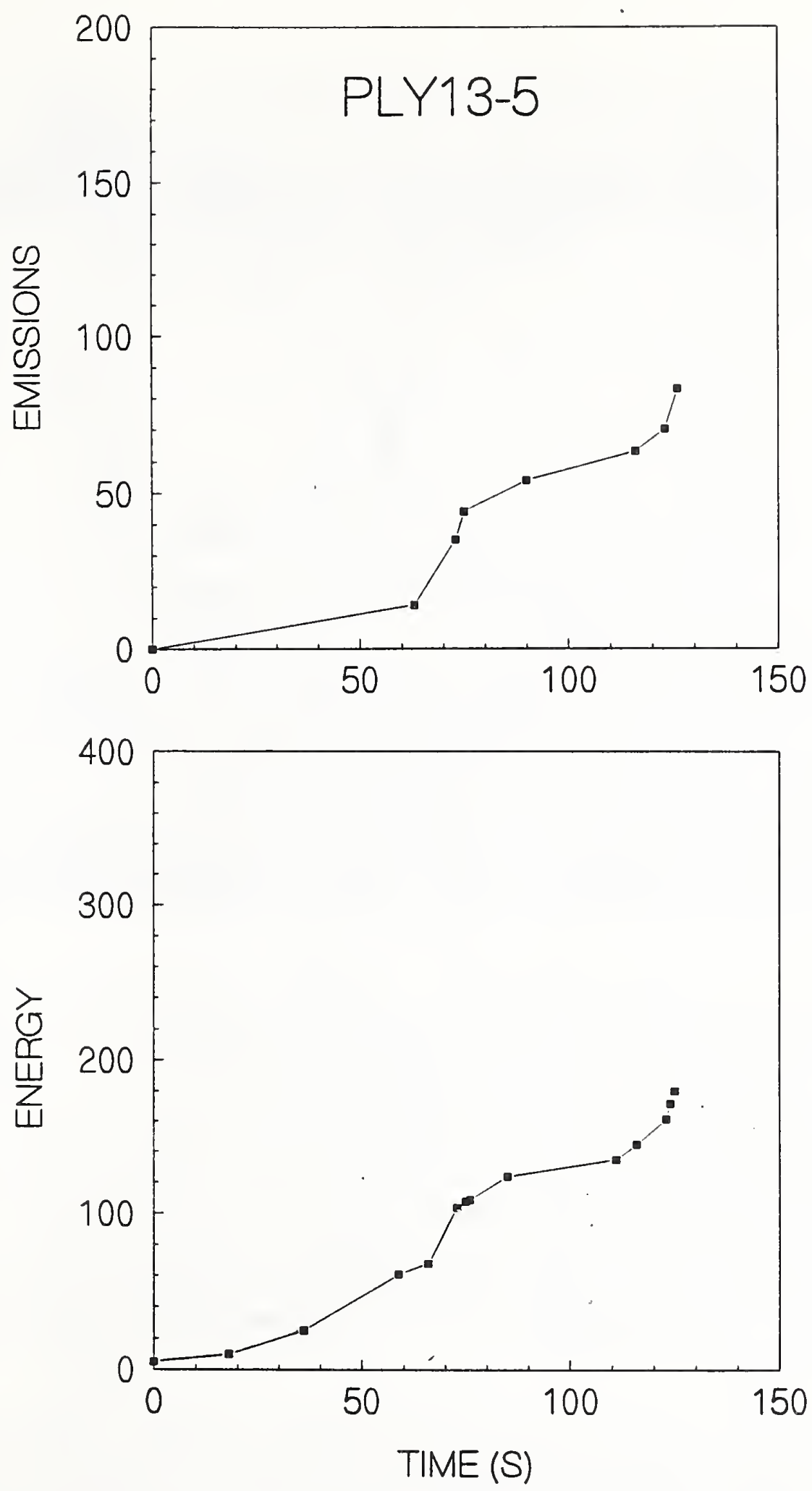

Figure 4. Number of emissions and cumulative energy from $13 \mathrm{~mm}$ thick plywood sample heated with $1.1 \mathrm{~kW}$ flame. 

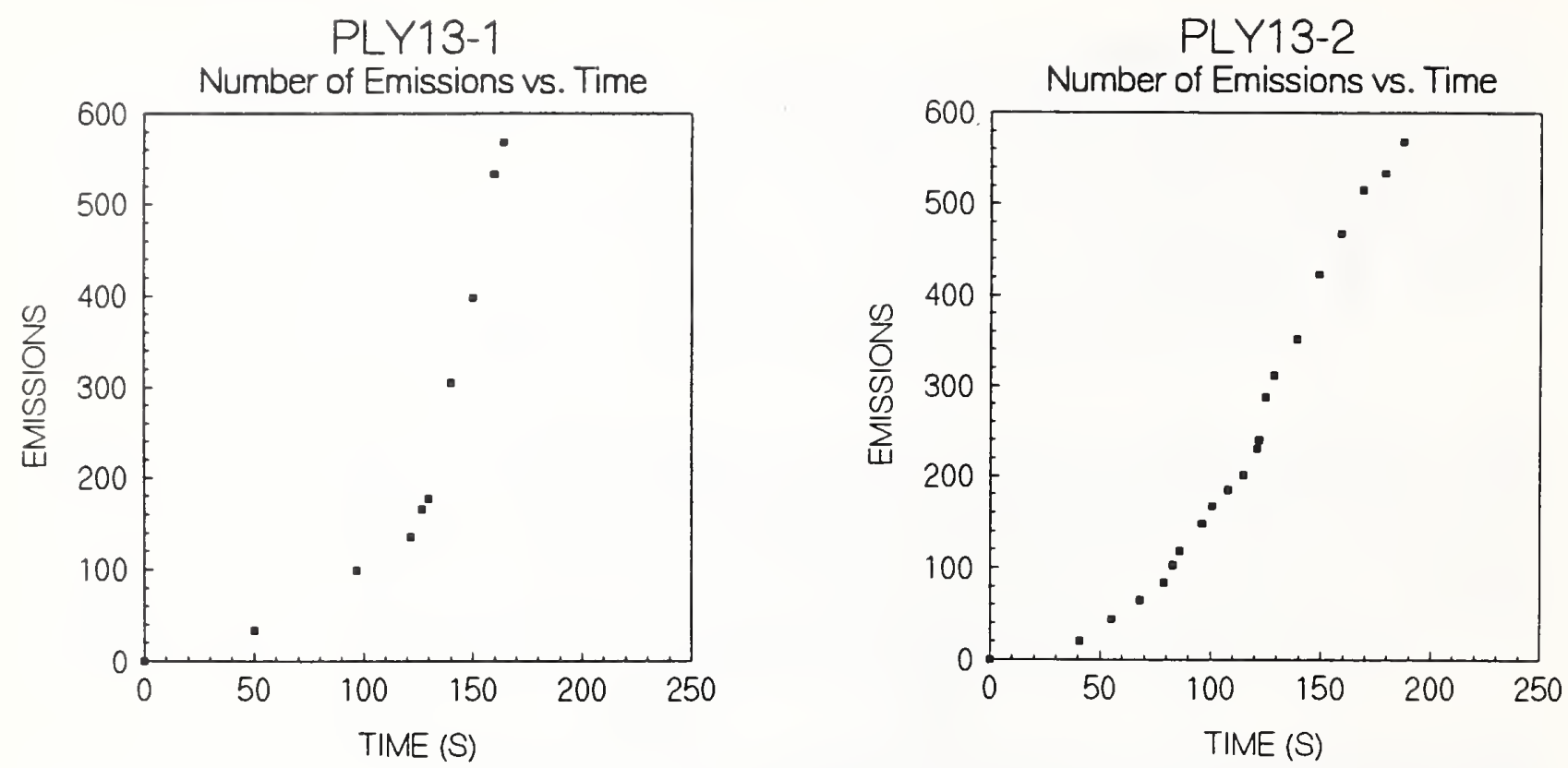

PLY13-3
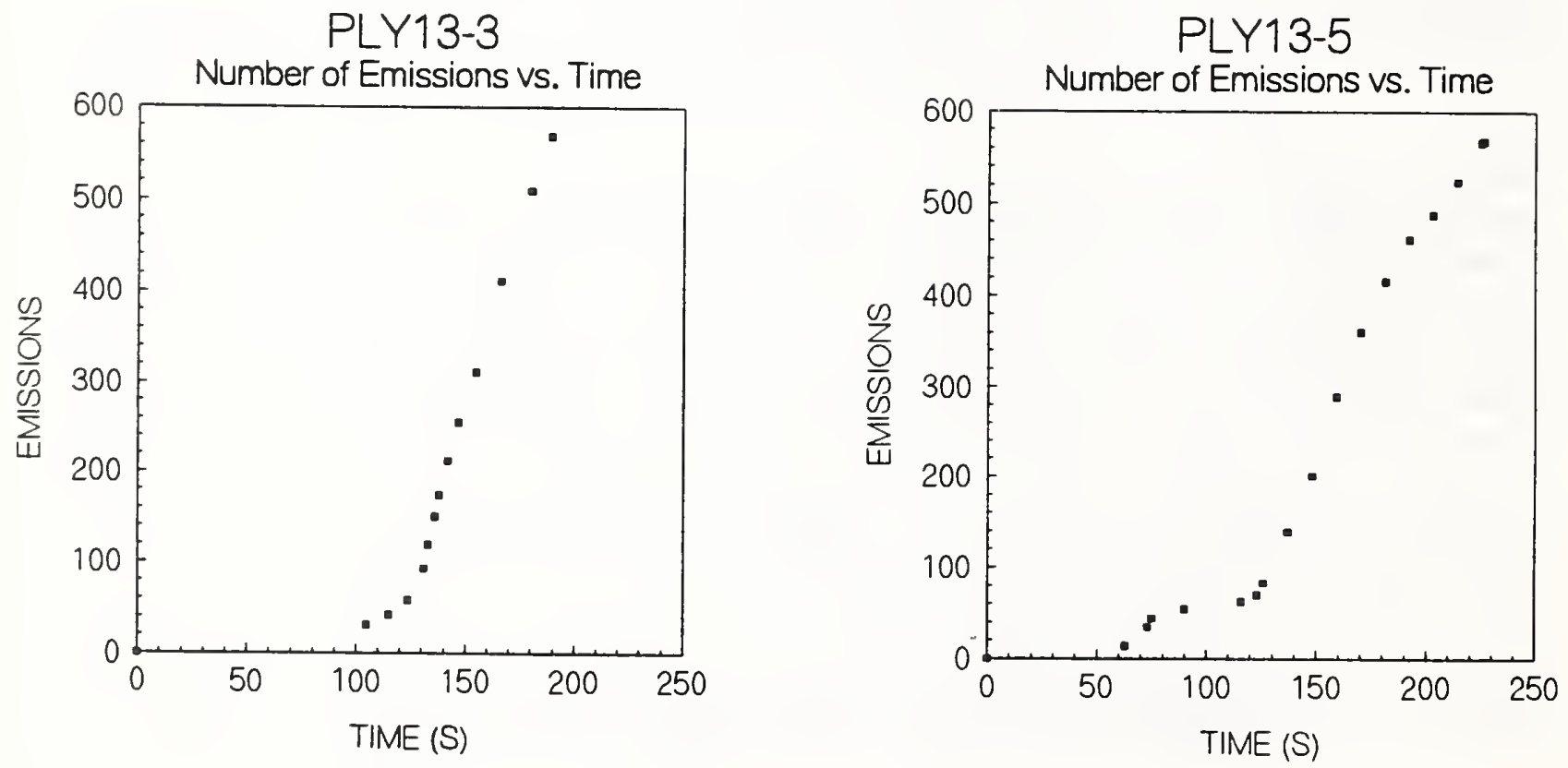

Figure 5. A comparison of $A E$ events from duplicate samples of $13 \mathrm{~mm}$ thick plywood under identical operating conditions. 
Table 2. Summary of accumulated energy and number of emissions for $13 \mathrm{~mm}$ thick plywood tests

\begin{tabular}{||l|l|l|l||}
\hline Test Number & $\begin{array}{l}\text { Cum. Energy after 2 } \\
\text { minutes of Heating }\end{array}$ & $\begin{array}{l}\text { Emissions/minute } \\
\text { during Heating }\end{array}$ & $\begin{array}{l}\text { Emissions/minute } \\
\text { during Cooling }\end{array}$ \\
\hline PLY13-1 & 870 (arb. units) & $42 /$ min. & $427 /$ min. \\
\hline PLY13-2 & 519 & 63 & 180 \\
\hline PLY13-3 & 95 & 10 & 265 \\
\hline PLY13-5 & 150 & 32 & 220 \\
\hline PLY13-6 & 63 & 5 & 151 \\
\hline
\end{tabular}

tape holding the thermocouples in place to lose its adhesive property. A large number of emissions were recorded at this time which could be attributed to the tape de-bonding.

In the case of the $13 \mathrm{~mm}$ aluminum plate, there were no emissions during the first two minutes of heating; the test continued for four more minutes, during which only three emissions were measured. The average duration and energy of an individual event were $0.18 \mathrm{~ms}$ and 5.1 , and $0.52 \mathrm{~ms}$ and 16.7 , respectively, for the 2 and $13 \mathrm{~mm}$ aluminum samples. These tests suggest that for a uniform material like aluminum, the number of events is inversely related to the time for the thermal wave to propagate through the material, while the energy and duration associated with an individual event increase approximately as the square root of the material thickness.

General trends regarding the effect of total sample thickness on the acoustic emission from plywood are more difficult to ascertain. The $13 \mathrm{~mm}$ samples averaged about 30 emissions/min. The $19 \mathrm{~mm}$ thick sample produced about 10 emissions/min on average, a decrease in line with what was observed in the aluminum tests. However, a single experiment using a $6 \mathrm{~mm}$ beam of plywood only produced about 2 emissions $/ \mathrm{min}$. Even if one considers the reduction in the number of plies from five to three when comparing the behavior of the 13 and $6 \mathrm{~mm}$ beams, one would expect more activity from the thinner sample. The average duration and energy released in an individual event increase with thickness approximately as in the aluminum tests. These data are summarized in Table 3. Additional tests are required to determine if the behavior observed in the $6 \mathrm{~mm}$ sample is typical or simply a random fluctuation.

The acoustic emission varied widely among the different materials. Two sets of experiments were run with three different materials of the same thickness and with the same open flame. The difference in response of two different $6 \mathrm{~mm}$ thick plastics, poly-vinylchloride and poly-methylmethacrylate, was striking. The PVC showed very little activity (4 emissions/min, cumulative energy of 27), while the PMMA produced 52 emissions/min and accumulated 1065 units of energy released. (Recall that the $6 \mathrm{~mm}$ thick plywood produced 2.5 
emissions/min and released a total of 18 units of energy.) In both these tests, a $2 \mathrm{~mm}$ aluminum plate was placed directly under the plastic to prevent sagging of the specimen, and no doubt contributed to the acoustic emission. For comparison, a test was run on PMMA without the aluminum sheet. Half the number of emissions were recorded, and one tenth the energy was released. It was not possible to heat an unsupported PVC sample without severe sagging occurring.

One test was run using an unsupported, $2 \mathrm{~mm}$ thick phenolic plastic. The sample was of slightly different size (see Table 1 ) and was perforated uniformly ( $2 \mathrm{~mm}$ holes, $2.2 / \mathrm{cm}^{2}$ ).

Table 3. Effect of material thickness on AE from plywood

\begin{tabular}{|l|l|l|l|l|}
\hline thickness & $\begin{array}{l}\text { emissions/min } \\
\text { during heating }\end{array}$ & $\begin{array}{l}\text { cumulative energy } \\
\text { after } 2 \text { minutes }\end{array}$ & $\begin{array}{l}\text { average energy } \\
\text { released/event }\end{array}$ & $\begin{array}{l}\text { average dura- } \\
\text { tion/event }\end{array}$ \\
\hline $6 \mathrm{~mm}$ & $2.5 / \mathrm{min}$ & 18 (arbitrary units) & 3.6 (arbitrary units) & $0.08 \mathrm{~ms}$ \\
\hline $13 \mathrm{~mm}$ & $30 / \mathrm{min}$ & 339 & 5.6 & $0.15 \mathrm{~ms}$ \\
\hline $19 \mathrm{~mm}$ & $10 / \mathrm{min}$ & 46 & 7.0 & $0.66 \mathrm{~ms}$ \\
\hline
\end{tabular}

The flame was removed after only 45 seconds of heating because of the large amount of smoke produced. In this short period 91 emissions $(121 / \mathrm{min})$ were recorded with a cumulative energy of over 1500 units. Additional tests are required to separate the influence of the holes from that of the material, but, clearly, phenolic circuit boards have a great propensity for acoustic emission.

The activity of six different $13 \mathrm{~mm}$ thick samples of gypsum board was compared to the aluminum and plywood specimens already discussed. The average number of emissions was $19 / \mathrm{min}$ (compared to $30 / \mathrm{min}$ for the plywood and $0 / \mathrm{min}$ for the aluminum), and the average cumulative energy was 137 (compared to 339 for the plywood and 0 for the aluminum). While it appears that the gypsum is about half as responsive as the equivalent thickness plywood, one gypsum sample produced $99 \mathrm{AE}$ events during the two minute heating period. Another sample exhibited no emissions when it was heated under the same set of conditions, but when the flame was brought closer, much AE activity was recorded. These tests reconfirmed the random nature of acoustic emission from heterogeneous materials, and that moisture content could be a factor since the tests were conducted on different days with no attempt to control the humidity. The increased activity caused by placing the flame closer to the surface suggests the obvious conclusion that heat flux is an important parameter in creating thermal stress. 


\section{Effect of Heat Flux}

The influence of heat flux on the emission of acoustic energy was determined using a solid wooden beam with a $37 \mathrm{~mm}$ by $88 \mathrm{~mm}$ cross-section (standard fir $2 \times 4$ ). The baseline condition was the $1.1 \mathrm{~kW}$ flame, the same flame which was used in all the other material tests. The initial heat flux into the beam can be estimated by using the following expression ${ }^{12}$ for the convective heat transfer coefficient, $h$ :

$$
\mathrm{h}=0.68(\mathrm{k} / \mathrm{w}) \operatorname{Re}_{\mathrm{w}}{ }^{.47} \operatorname{Pr}_{\mathrm{f}}{ }^{.33}
$$

The Reynolds number, Re, is based upon the width of the board, $w$, and the average approaching mass flux of hot gas; the Prandtl number, $\mathrm{Pr}$, is the ratio of the viscosity and thermal diffusivity evaluated at $1200 \mathrm{~K}$; and $\mathrm{k}$ is the average thermal conductivity of the combustion products. $\mathrm{Re}$ is estimated to be about 188 , yielding a heat transfer coefficient of about $6.2 \mathrm{~W} / \mathrm{m}^{2}-\mathrm{K}$. This produces an initial heat flux of $11.4 \mathrm{~kW} / \mathrm{m}^{2}$, or about $7.4 \%$ of the heating value of the natural gas is transferred to the $88 \mathrm{~mm} \mathrm{x} 88 \mathrm{~mm}$ area of the wooden beam just above the burner. As the temperature of the surface increases, the heat flux decreases unless the wood ignites. For the highest heat fluxes, sustained ignition occurred within $30 \mathrm{~s}$; for the lowest natural gas flows no fire was observed, just smoke; and for two intermediate cases, flames appeared to be emanating from the wood but ceased once the gas burner was removed.

Figures $6 \mathrm{a}$ and $6 \mathrm{~b}$ are plots of the number of $\mathrm{AE}$ events and the cumulative acoustic energy released during the highest rate of heating. The number of events increases exponentially with time after only $20 \mathrm{~s}$ of heating, and reaches a total of 568 (the maximum storage level of the instrument) in about $45 \mathrm{~s}$, a rate more than double what was observed with the $13 \mathrm{~mm}$ thick plywood sample. The total acoustic energy released approaches 3000 in this time interval.

The emissions per minute over the two minute heating period and the cumulative energy released 44 seconds into the heating are plotted as a function of the estimated initial heat flux in Figure 7. The expected trend is for both the rate of emission and the cumulative energy released to increase with the heat flux. The deviation in the cumulative energy for the 10.8 $\mathrm{kW} / \mathrm{m}^{2}$ case (note that $\mathrm{E}$ is reduced a factor of ten on the graph for this one data point) can be traced to the increased number of knots and imperfections located near the point of heat input. Sap could be observed leaking from the knotty areas, audible crackling was heard, and small chips of wood were noted to fly out of the sample during the burning stage of the test. The large differences in $\mathrm{E}$ for the two highest fluxes also points out the dependence of the $\mathrm{AE}$ process on the particular specimen used, although the variation in the number of emissions is not too great in this case. 


\section{OBSERVATIONS AND CONCLUSIONS}

Acoustic emission is an established technique for monitoring microscopic motion of solids subjected to thermal stress. The experiments have shown that for common materials exposed to small flames, the AE activity is sufficiently strong in most cases to detect remotely the presence of the heat source before a measurable rise in temperature occurs.

The general behavior of the materials studied can be explained qualitatively by comparison to the simplified theory developed by $\mathrm{Clough}^{11}$ which predicts acoustic emission during laser heating of a surface. In particular the following trends are consistent with most of the limited amount of data collected:

- the energy detected increases about quadratically with increasing heat flux

- the energy detected increases with the material parameter $(\Gamma B v)^{2} /\left(\mathrm{ckC}_{\mathrm{p}}\right)$

- the energy detected decreases with increasing sample thickness

The number of emissions/minute varies for a given material in a manner similar to the energy. However, the absolute number of emissions can not be predicted a priori because the number of defects and the moisture content are highly variable for heterogeneous materials. The contribution of phase change to the emission from polymeric materials is also difficult to predict.

The relative ranking of AE activity in the structural materials investigated, in decreasing order, is as follows: wooden $2 \times 4>$ phenolic circuit board $>$ plywood $>$ PMMA $>$ gypsum board $>$ PVC $>$ aluminum. Because acoustic emission is a statistical event, however, the ranking could easily reverse for a particular set of specimens.

There are several key items that have to be addressed before AE sensing of fires could be practical. The most critical is the signal-to-noise ratio. Under the conditions in the current series of tests, no effort was made to isolate the laboratory from background noises such as the sounds from air conditioning, human voices and movement in the room, exhaust fans, doors opening and closing, or telephones ringing. The number of emissions detected by the $\mathrm{AE}$ sensors during an initial 2 minute period prior to heating was rarely greater than one, and when left overnight the instrument would record spurious signals at a rate of $0.3 /$ minute, which is a factor of ten below the emissions measured from the least sensitive flammable material, even when one considers the large variability among different samples of the same material. If an object were to fall directly on the sample beam, multiple strong events would be detected by the sensors. As long as these did not occur often, a fire detector could be trained to ignore isolated high energy events. 

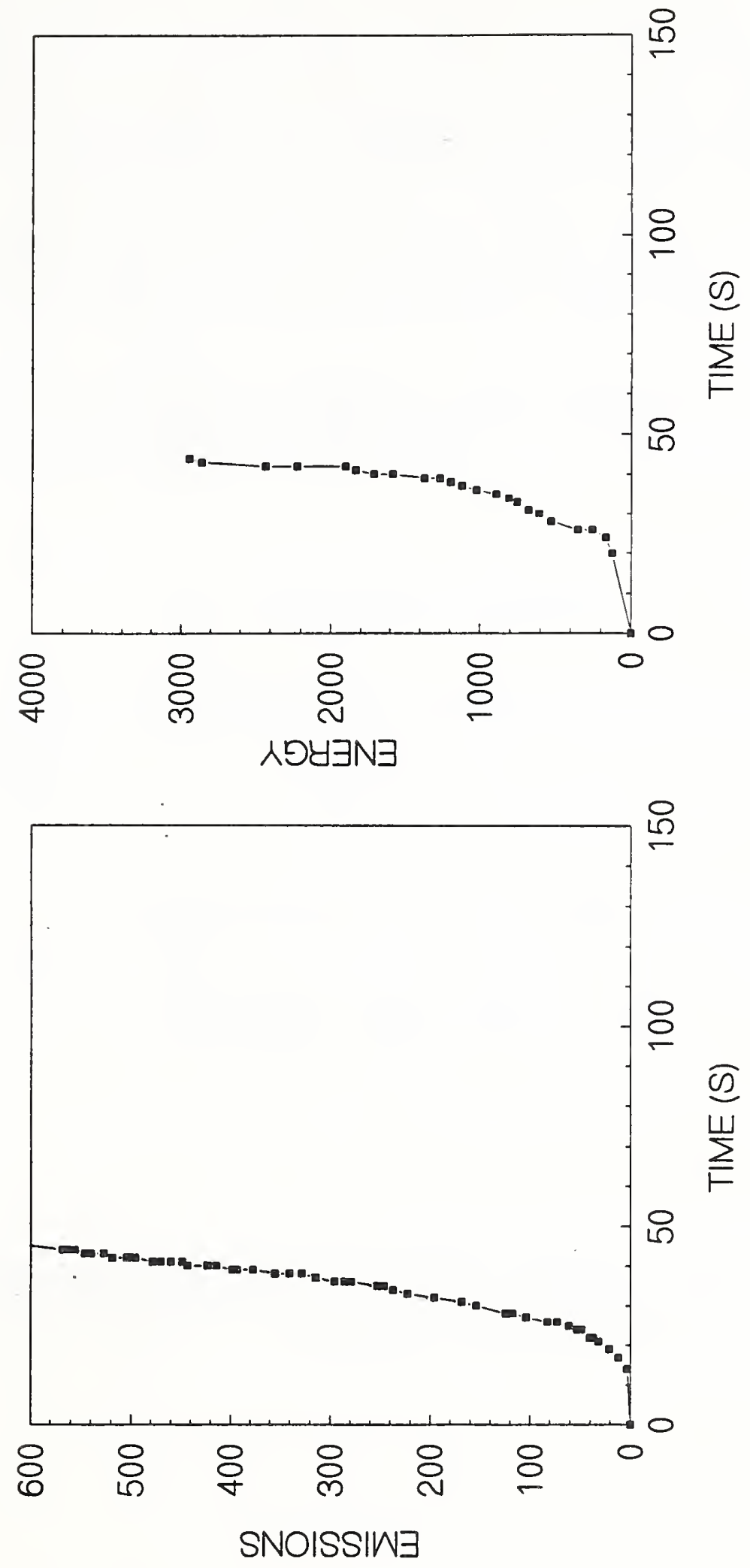

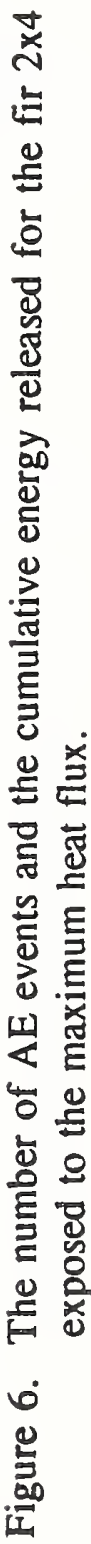




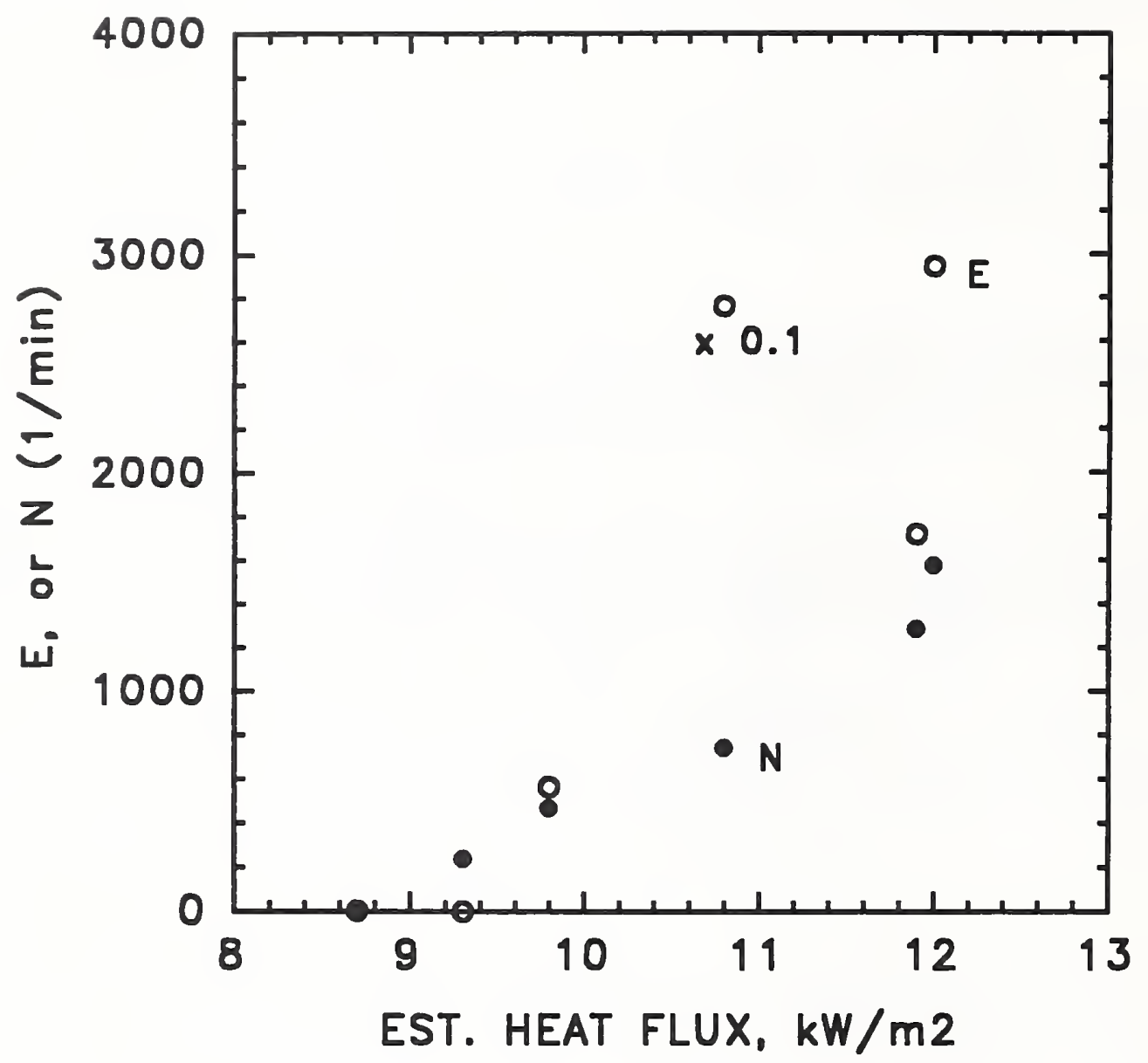

Figure 7. The effect of heat flux (estimated from eq. 2) on the number of emissions and the cumulative energy released from fir $2 \times 4$ samples. Solid circles are the number of emissions, $\mathrm{N}$, and open circles are the energy, $\mathrm{E}$. 
A second issue is the size of the area which one AE transducer can monitor. The heat source was $0.3 \mathrm{~m}$ removed for these tests. Since the acoustic wave for materials with high internal damping loses energy in proportion to distance, one could extrapolate that at a distance of $3 \mathrm{~m}$ the signal would decrease to the level of the noise. Complex geometries and the number of interfaces between the source and the transducer would certainly affect this estimate.

Cost and maintenance are additional factors which could limit AE fire detection. The PAC system used in this work is a research instrument which would not be suitable for untended field application. However, one processor could serve a large number of transducers, so that applications to high value equipment protection may be economically justifiable.

It has been shown by this study that a fire can be sensed by acoustic emission, and that $\mathrm{AE}$ may respond faster than conventional fire detectors for some hidden smoldering fires. More research is required, though, to determine the appropriate role for this unique system in fire protection.

\section{ACKNOWLEDGEMENT}

The authors wish to acknowledge Dr. Roger Clough of the Materials Science and Engineering Laboratory, who provided the acoustic emission measuring equipment and guidance for its application. 


\section{REFERENCES}

1. Hamins, A., J.C. Yang, and T. Kashiwagi, "An Experimental Investigation of the Pulsation Frequency of Flames," Twenty-fourth Symposium (International) on Combustion, paper no. 194, Sydney, Australia, July 5-10, 1992.

2. Detriche, P., and J.C. Lanore, "An Acoustic Study of Pulsation Characteristics of Fires," Fire Technology 16, (1980) 204.

3. Ramohalli, Kumar, "Efficient Burner Characterization by Acoustic Measurements," Western States Section/Combustion Institute, paper 78-22, Boulder, CO, April, 1978.

4. $\quad$ Redding, R.J., "Sound Beams for Fire Alarm and Gas Detection Systems," Fire 72, no. 897, (1980) 532-533.

5. Grosshandler, W.L., "An Assessment of Technologies for Advanced Fire Detection," Heat and Mass Transfer in Fire and Combustion Systems, P. Cho and J. Quintiere, eds., American Society of Mechanical Engineers, HTD-Vol. 223, 1992, 1-10.

6. Wadley, H.N.G., "Acoustic Emission: Nature's Ultrasound," in Review of Progress in Quantitative Nondestructive Evaluation, Vol. 5A, D.O. Thompson and D.E. Chimenti, Eds., Plenum Publishing Corp., 1986, pp. 271-293.

7. Wadley, H.N.G., and J.A. Simmons, "Microscopic Origins of Acoustic Emission," 1984.

8. Wade, A.P., D.B. Sibbald, M.N. Bailey, R.M. Belchamber, S. Bittman, J.A. McLean, and P.D. Wentzell, "An Analytical Perspective on Acoustic Emission," Analytical Chemistry 63, May 1, 1991, 497A-507A.

9. Clough, Roger B., H.N.G. Wadley, and R. Mehrabian, "Acoustic Emission Studies of Electron Beam Surface Modification of Aluminum, "Metallurgical Transactions B, 19B, (1988) 493-503.

10. Wu, Wen-li, "Thermoacoustic Technique for Determining the Interface and/or Interply Strength in Polymeric Composites," SAMPE Journal 26, no. 2, (1990) 11-15.

11. Clough, R.B., "The Energetics of Acoustic Emission Source Characterization," Materials Evaluation 45, (1987) 556-563.

12. Holman, J.P., Heat Transfer, seventh edition, Mcgraw-Hill Publishing Co., New York, 1990, p. 302. 


\begin{tabular}{|c|c|c|}
\hline \multirow[t]{3}{*}{$\begin{array}{l}\text { NIST-114A } \\
\text { (REV. 3-90) }\end{array}$} & \multirow{3}{*}{$\begin{array}{l}\text { U.S. DEPARTMENT OF COMMERCE } \\
\text { NATIONAL INSTITUTE OF STANDARDS AND TECHNOLOGY } \\
\text { BIBLIOGRAPHIC DATA SHEET }\end{array}$} & $\begin{array}{ll}\text { 1. } & \text { PUBLCCATION OR REPORT NUMEER } \\
\text { NISTIR } 4984 \\
\text { 2. } & \text { PERFORMINO ORGANIZATION REPORT MUMB }\end{array}$ \\
\hline & & \\
\hline & & December 1992 \\
\hline
\end{tabular}

4. TITIE AND SUBTITLE

\section{Acoustic Emission of Structural Materials Exposed to Open Flames}

5. AUTHOR(S) William Grosshandler and Margaret Jackson

\begin{tabular}{l|l|l|}
\hline 6. PERFORMINO ORQANIZATION (IF JOINT OR OTHEA THAN NIST, SEE INSTRUCTIONS) & 7. CONTAACT/ORANT NUMBER \\
U.S. DEPARTMENT OF COMMERCE \\
MATIONAL INSTITUTE OF STANDAROS AND TECHMOLOQY \\
GATHERSBURG, MD 20890 & 8. TYPE OF REPOAT AND PERIOD COVERED \\
\hline
\end{tabular}

9. SPONSORING ORQANIZATION MAME AND COMPLETE ADDRESS (STREET, CITY, STATE, ZIP)

10. SUPPLEMENTARY NOTES

11. ABSTRACT (A 2OO-WOAD OA LESS FACTUAL SUMMARY OF MOST SIONIFICANT IMFORMATION. IF DOCUMENT INCLUDES A SIGMIFICANT BIBLLOQRAPHY OR UTERATURE SURVEY, MENTION IT HERE)

The use of acoustic emission ( $\mathrm{AE})$ as an early indicator of a hidden structural fire has been investigated and found to be a viable, but undeveloped, concept. Piezoelectric transducers have been mounted directly on $0.5 \mathrm{~m}$ long, simply support beams of different structural materials (aluminum, gypsum board, wood and plastic), and have been used to record ultrasonic events resulting from a small flame placed under the beam. The number of $\mathrm{AE}$ events in a minute and the cumulative energy released during the heating cycle provide a good measure of the overheated state of some of these materials even before a temperature increase is indicated. The measured signals varied in energy and number with the type of material, the thickness of the specimen and heat flux. Wood was particularly susceptible to acoustic emission, producing more than 1000 events per minute in the solid fir board and 30/min in the $13 \mathrm{~mm}$ thick plywood when the flame exceeded $1.0 \mathrm{~kW}$. The gypsum board produced 16 events in a minute. The aluminum plate did not respond above the background level ( 0.3 events/minute) even though it reached the highest temperature. The differences in cumulative energy were equally striking, with the plywood being four times more energetic than the gypsum board even though the heating period for the wood was half as long, and 30 times more energetic than the aluminum. The critical issues which remain to be investigated before this technique can be adapted to practical fire detection applications are mentioned.

12. KEY WORDS (6 TO 12 ENTRIES; ALPHABETICAL ORDER; CAPITALIZE OMLY PAOPER MAMES; AMD SEPARATE KEY WORDS BY SEMICOLONS)

Fire detection, acoustic properties, acoustic sensors, material properties

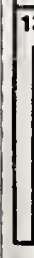

AVALABIUTY

UNUMUTED

FOR OFFICLAL DISTRIBUTION. DO NOT RELSASE TO MATIONAL TECHNICAL IMFORMATION SERVICE (NTIS).

ORDER FROM SUPERINTENDENT OF DOCUMENTS, U.S. GOVERMMENT PAINTINO OFFICE, WASHINOTON, DC 20402.

ORDER FROM MATIOMAL TECHMICAL IMFORMATION SERVCE (MTIS), SPRINGFIELD, VA 22161.

\begin{tabular}{|c|} 
14. NUMBER OF PRINTED PAQES \\
26 \\
\hline 15. PAICE \\
$\mathrm{AO} 3$
\end{tabular}




